\title{
La voz de los vencidos: mito y memoria en la trama oral del Centro Cultural Gabriela Mistral (1971-2010)
}

\section{The voice of the vanquished: myth and memory in the oral plot of the Gabriela Mistral Cultural Center (1971-2010)}

\author{
Elías Sánchez González*
}

\begin{abstract}
Resumen: La reconversión del Centro Cultural Gabriela Mistral (GAM), dio cuenta de una serie de estratos del tiempo empirizados en distintas denominaciones y transformaciones a nivel estético y simbólico desde 1971 al 2010. Siendo las más importantes a la fecha, las de la Unidad Popular y la Dictadura Militar. En este artículo, exploraremos la forma en la que algunos de sus protagonistas (de izquierda), han organizado y representado sus experiencias. Para ello, utilizamos el dúo mito - memoria para adentrarnos en las formas de representación y articulación de estos pasados presentes.
\end{abstract}

Palabras claves: Unidad Popular, Dictadura, Mito, Memoria, Pasados Presentes.

\begin{abstract}
The reconversion of the Gabriela Mistral Cultural Center (GAM), gave account of a series of strata of time empirizados in different denominations and transformations at aesthetic and symbolic level from 1971 to 2010. Being the most important to date, those of the Popular Unity and the Military Dictatorship. In this article, we will explore the way in which some of its protagonists (left) have organized and represented their experiences. To do this, we use the mito - memory duo to delve into the forms of representation and articulation of these past tenses.
\end{abstract}

Keywords: Unidad Popular, Dictatorship, Myth, Memory, Past Presents.

Recibido: 8 diciembre 2017

Aceptado: 16 abril 2018

* Chileno, Licenciado en Historia mención Estudios Culturales (UAHC-Chile). Magister en Historia y Memoria, Facultad de Humanidades y Ciencias de la Educación, Universidad Nacional de La Plata. Doctorando en Historia de la FaHCE- UNLP. Becario Doctoral CONICET 2013-2018, Argentina. Becario en Instituto de Investigaciones y Políticas del Ambiente Construido (IIPAC - CONICET), Facultad de Arquitectura y Urbanismo -Universidad Nacional de La Plata, Argentina. elias.sanchez27@gmail.com 


\title{
Introducción
}

\begin{abstract}
"Un mito, no es necesariamente un relato falso o un cuento inventado; más bien es un relato que, verídico o no, extiende el significado simbólico de un evento individual para darle forma narrativa a las auto-representaciones compartidas de una comunidad y una cultura"2
\end{abstract}

El trabajo de investigación que realizamos ${ }^{3}$, buscó extraer y profundizar el estudio de los estratos del tiempo sedimentados en el Centro Cultural Gabriela Mistral (GAM) ${ }^{4}$, a través del relato de algunos de sus protagonistas de izquierda (1971-2010) ${ }^{5}$. Para ello, hemos recopilado y trabajado con entrevistas a arquitectos, trabajadores de la construcción y artistas que participaron de su construcción y del gobierno de Salvador Allende Gossens (1970-1973). Por un lado, examinamos los testimonios y artículos recogidos por Paulina Varas y José Llanos en la obra «275 días. Sitio, Tiempo, Contexto y Afecciones Afectivas. Santiago: Ograma - MOP, 2011» ${ }^{6}$. Por otro lado, entrevistas que realizamos entre el 2012 y 2014 y los textos testimoniales ${ }^{7}$ que abrieron la obra compilada por Paulina Varas y José Llanos y que acompañaron la artealización de los distintos estratos del tiempo y afecciones que el trabajo curatorial quiso plasmar en el reconvertido Centro Cultural en su inauguración el 2010.

\footnotetext{
${ }^{2}$ Alessandro Portelli, Historias orales. Narración, imaginación y diálogo, Rosario, Argentina: Prohistoria ediciones - FaHCE UNLP, 2016, p., 134

${ }^{3}$ Este artículo se enmarca en el proyecto de investigación conducente al título de Magister en Historia y Memoria que desarrolle en mi estancia en Argentina en el marco de una Beca Doctoral tipo I y II 2013-2018, Título: Historia, Memorias y Ciudad. Las huellas del pasado reciente en Santiago de Chile y Buenos Aires Argentina, 1970-2010. El Edificio UNCTAD III y la Escuela de Mecánica de La Armada (Ex - ESMA). Director: Dr. Arq. Gustavo San Juan (IIPAC-UNLP). Co-Directo: Dra. Patricia Flier (FaHCE-UNLP).

${ }^{4}$ Este complejo arquitectónico se ubica en la zona céntrica de la ciudad de Santiago. Al costado del Cerro Santa Lucía por la Av. Bernardo O’Higgins, colindante al Barrio Lastarria. Pese a las distintas transformaciones y reconversiones que atestigua, el complejo sigue siendo una obra compuesta por 2 estructuras, una Torre de 22 pisos y otro edificio más bajo de perfil horizontal contiguo en forma de placa. 5 Hace unos años presentamos un avance introductorio sobre estos estratos: Sánchez, Elías. "Las huellas del Pasado Reciente de Santiago de Chile. Historia(s) y Memoria(s) del Centro Cultural Gabriela Mistral (GAM) 1971-2010". En Flier, Patricia (Ed.): Dilemas, apuestas y reflexiones teórico-metodológicas para los abordajes en Historia Reciente. FaHCE-UNLP: Ensenada, Argentina 2014, pp. 168-196

${ }^{6}$ Llano, José. "Conversación con los Arquitectos de la UNCTAD III, Hugo Gaggero y José Covacevic". En Varas, P., \& Llano, J. 275 días. Sitio, Tiempo, Contexto y Afecciones Afectivas. Santiago: Ograma - MOP, 2011. Varas, Paulina. "El nosotros como arte incorporado a la arquitectura y como arte incorporado a la vida". Varas, P., \& Llano, J. op. cit.

7 "Encuentro sobre UNCTAD III". Textos Protagonistas. Lawner, Miguel (2010); Assler, Federico (2010); Bustamante, Manuel (2010); Frías, Miguel (2010). Presentación del proyecto curatorial Museo de la Memoria y los Derechos Humanos, Santiago, junio 2010. En Varas, P., \& Llano, J. op. cit. Wong, Jorge. Edificio UNCTAD III. En Varas, P., \& Llano, J. op. cit. Guerra, Eduardo. Conversaciones con Eduardo Guerra, entrevista realizada por Paulina Varas En Varas, P., \& Llano, J. op. cit.
} 
A partir de esta polifonía, utilizamos el dúo mito - memoria para analizar la forma en que estos actores organizaron su relato. Como lo advierte Nora Rabotnikof ${ }^{8}$, resulta problemático diferenciar mito y memoria, más todavía su articulación, sobre todo atendiendo al universo político que involucran pasados difíciles o "pasados presentes"9 como el que acá tratamos. En primer lugar, por la institucionalización que desde el poder se hace del pasado y esto, inevitablemente, involucra ejercicios de transmisión cultural del pasado. En segundo lugar, pese a las simetrías, para Carlos Altamirano "(...) la construcción de una memoria colectiva tiende siempre algo de batalla por el nombre que debe darse a los hechos" 10 . En otras palabras, mito y memoria se conjugan como una forma de transmisión cultural, que para nuestro caso, lo utilizamos para adentrarnos en una "forma de vivir el mundo histórico", o lo que Rabotnikof llama "una manera diferente de articular pasado, presente y futuro" $"$.

La memoria, por un lado, tiene como objetivo la elaboración del pasado (la historia como disciplina también, aunque esta última, lo hace desde una posición crítica y ecuánime $)^{12}$. Por otro lado, como relato articulado del pasado con el presente (en la fórmula de Paul Ricoeur ${ }^{13}$ : la memoria es el presente de un pasado ausente), tiene una capacidad informativa que escapa a los relatos históricos. En palabras de Dominick LaCapra “(...) el sentimiento de una experiencia, la intensidad de la alegría o del sufrimiento, la cualidad de lo que sucede"14. Asimismo, por último, la Memoria es una "categoría social"15 que da cuenta de un trabajo, del esfuerzo por construir una semántica, sobre todo atendiendo aquellos acontecimientos capaces de destruir identidades y ocultar tras el trauma y la vergüenza nuestras experiencias. Al mismo tiempo, el mito, al igual que la memoria, es presentado en oposición a la verdad. En palabras de Manuel Javier Amaro Barriga:

(...) las mentes creadoras en general, y quienes cultivan la literatura en particular, han demostrado a lo largo de siglos que existen diversas formas de expresar las creencias, los temores, los sufrimientos, las esperanzas y, genéricamente, las pulsiones humanas, lo que significa que el hombre es capaz de transformar sus vivencias y experiencias en verdades colectivas mediante la fabulación, aunque ésta no sea comprobable científica o racionalmente, lo que, por otra parte, no debe obstar para reconocer en ella la cimentación y

\footnotetext{
${ }^{8}$ Nora Rabotnikof. "Mito político y memorias de la política", en María Inés Mudrovcic (editora). Pasados en conflicto. Representación, mitos y conflicto. Argentina: Prometeo libros, 2009.

${ }^{9}$ Carlos Altamirano. "Pasado presente". En Lida, Clara; Crespo, Horacio y Yankelevich, Pablo. Argentina 1976, Estudios entorno al Golpe de Estado. México D.F.: El Colegio de México, Centro de Estudios Históricos, 2007.

${ }_{11}^{10}$ Altamirano. Op. Cit., p. 22

${ }^{11}$ Rabotnikof. Op. Cit. p. 109

${ }^{12}$ Enzo Traverso. "Historia y Memoria". Notas sobre un debate. En M. Franco, \& F. Levín, Historia Reciente. Perspectivas y desafios para un campo en construcción. Buenos Aires: Paidos.2007, p.72

${ }^{13}$ Paul Ricoeur. La memoria, la historia, el olvido. Buenos Aires: Fondo de Cultura Económica, 2010.

${ }^{14}$ Dominick LaCapra. Historia y memoria después de Auschwitz. Buenos Aires, Argentina: Prometeo libros. 2009., p.34

${ }^{15}$ Elizabeth, Jelin. Los trabajos de la memoria. Madrid: Siglo XXI. 2002, p.30
} 
posterior asimilación precisamente de aquello, de una verdad social aceptada y compartida. $^{16}$

El tipo de relato con el cual nos relacionamos intenta una revalorización de la memoria de la Unidad Popular (UP) ${ }^{17}$, aprovechando el momento en el que explotó el pasado: el incendio del Edificio Diego Portales y su reconversión en Centro Cultural Gabriela Mistral (2006-2010). De ahí la conexión y articulación con el pasado, en específico el acto de construcción y funcionamiento del complejo arquitectónico entre 1971 y 1973, como Centro Cultural Metropolitano Gabriela Mistral. En este caso, nuestro mito se acerca más a una representación del pasado en términos de amigos y enemigos:

“(...) un rasgo que diferenciaría al mito de la aproximación de la historia como disciplina (¿también de la memoria?) es la articulación narrativa de una serie de momentos, episodios, personajes en una historia con tintes épicos (...) ese mito es una historia de buenos y malos, o dicho de manera menos caricatural, una narración armada en términos de amigos y enemigos. La historia que se cuenta y el pasado que se representa es un pasado conflictivo, desgarrado, escindido y en ocasiones directamente bélico. Sobre todo, como hace tiempo observara Schmitt en relación con las dos grandes ofertas míticas de su momento, habría una especie de estructura temporal orientada por otro mito, de carácter más general si se quiere, el de "la gran batalla decisiva, la batalla napoleónica que aplasta al enemigo" (Schmitt, 1923: 178)". ${ }^{18}$

En definitiva, podemos pensar -juntos a estos autores-, a la memoria como una forma de elaboración del pasado y el mito, al ser una configuración diferente y popular de representación de lo que sucedió, nos permite observar y analizar una forma distinta de revalorización de las memorias y otra forma de contar una historia.

Así, con estas voces tratamos de seguir el recorrido y las distintas denominaciones de un complejo arquitectónico, que de símbolo de la UP a partir de la realización de la UNCTAD III ${ }^{19}$, fue nombrado Centro Cultural Metropolitano Gabriela Mistral (19721973). Posteriormente, producto del golpe de Estado y la posterior instauración de una dictadura militar, los edificios pasaron a ser sede de gobierno del régimen militar entre

\footnotetext{
${ }^{16}$ Amaro Barriga, Manuel. "EL MITO EN LA CONSTRUCCIÓN CULTURAL". Fides et Ratio - Revista de Difusión cultural y científica de la Universidad La Salle en Bolivia. Fides Et Ratio v.2 n.2 La Paz sep., 2008 ISSN 2071-081X http://www.scielo.org.bo/scielo.php?script=sci_arttext\&pid=S2071-081X2008000100003., p.15

${ }_{17}^{17}$ Conglomerado político de izquierda que lideró Salvador Allende Gossens entre 1970 y 1973.

${ }^{18}$ Rabotnikof, op, cit, pp.111-112

${ }^{19}$ Conferencia Mundial de Comercio y Desarrollo UNCTAD III. Siglas en inglés: United Nations Conference on Trade and Development. Órgano dependiente de la Asamblea General de Las Naciones Unidas, creado en 1964 a petición de los llamados países subdesarrollados, siendo su objetivo principal -para aquellos añosmodificar el régimen de comercio internacional para que favoreciera a los países en vías de desarrollo (Documento: Comisión Chilena para la UNCTAD III. Servicio de prensa, abril y mayo de 1972, Santiago de Chile, Editorial Quimantú. Biblioteca Nacional de Chile, sección chilena, marzo 2011. que se realizó en Chile entre abril y junio de 1972).
} 
1973 y 1990, siendo bautizado como Edificio Diego Portales ${ }^{20}$. En la post dictadura, los edificios quedaron bajo control del Ministerio de Defensa, manteniendo el nombre del prócer decimonónico (1990-2006) que organizó y dio forma al Estado Autoritario. Esto hasta que un incendio en marzo del 2006 desmoronó una parte del complejo y permitió su reconversión en Centro Cultural nuevamente (2006-2010). ${ }^{21}$

Como un reloj parado que vuelve al movimiento, el incendio del entonces edificio Diego Portales propició que estos estratos se asociaran y cuestionaran, para hacer de este punto urbano una metáfora de la memoria y el momento de hacer pública una "pérdida no elaborada"22. En sus voces, observamos una forma de tramar (relatar), donde los acontecimientos son presentados en una urdimbre de cuestionamientos a la historia ¿Por qué esto ocurrió? ¿Por qué su proyecto fracasó? ¿Por qué fueron vencidos?

En primer lugar, presentaremos por qué al momento de su incendio los edificios fueron asociados a la figura de Augusto Pinochet. En segundo lugar, profundizaremos qué entendemos por mito y por qué lo utilizamos como estrategia de análisis hermenéutico para la trama oral de nuestros actores. Sostenemos como hipótesis, que sus testimonios se mueven entre la épica de su construcción, la tragedia que supuso la apropiación del complejo arquitectónico por las Fuerzas Armadas y la pérdida que significó su incendio y asociación en democracia con la figura de Augusto Pinochet.

\section{El edificio representa la dictadura de Augusto Pinochet}

Arq. José Covacevich: Hay ciertas cosas en las cuales podemos detallar, así para ir redondeando y asumamos un compromiso: si esta historia tiene un interés... y creo que es una historia interesante porque tiene que ver con periodos decisivos e importantes en los que nos tocó participar. Contemos esa historia para que se sepa... Porque, por ejemplo, y "aunque usted no lo crea", el edificio al terminarse tenía sus detractores y gente que lo defendía indistintamente. ¿Puede creer que hay gente que piensa que fue un edificio hecho por Pinochet? Te juro que haces una encuesta de repente y hay gente que dice que eso lo hizo Pinochet cuando estaba La Moneda cerrada. Errores sobre errores. Que la historia se cuente bien contada... ${ }^{23}$.

\footnotetext{
${ }^{20}$ Diego Portales (1793-1833), fue un comerciante y político decimonónico chileno, se le reconoce como el organizador del Estado, el que le dio forma con la constitución de 1833, la que sentó las bases de la política durante todo el Siglo XIX y gran parte del XX en Chile. Gabriel Salazar \& Julio Pinto, Historia contemporánea de Chile I, Estado, legitimidad, ciudadanía, Santiago, Chile: LOM, 1999.

${ }^{21}$ Lo que se quemó en el 2006 fue uno de los dos edificios que conformaron el complejo permitiendo al gobierno de Michelle Bachelet (2006-2010) su reconversión de Edificio Diego Portales a Centro Cultural Gabriela Mistral. Ver Sánchez González, Elías Gabriel. Juicio al Edificio Diego Portales. ¿Salvarlo o reemplazarlo? Incendio y reconversión del Centro Cultural Gabriela Mistral (2006-2010) como huellas del pasado reciente de Santiago de Chile. Tesis para optar al grado de Magister en Historia y Memoria. Facultad de Humanidades y Ciencias de la Educación, Universidad Nacional de La Plata. 2017. http://sedici.unlp.edu.ar/handle/10915/65181

22 Alessandro, Portelli, La orden ya fue ejecutada. Roma, las fosas ardeatinas, la memoria, Buenos Aires, Argentina: FCE, 2004, p., 295.

${ }^{23}$ José Llano. Op. cit., p.35 José Covacevic fue uno de los arquitectos que diseño y dirigió la construcción del complejo arquitectónico para la UNCTAD III y que posteriormente, durante el mismo gobierno de Allende,
} 
¿Por qué esta asociación? En varias oportunidades, otro de los protagonistas, el Arq. Miguel Lawner ex director de la CORMU ${ }^{24}$ (Corporación a cargo de la construcción de los edificios para la UNCTAD III y posterior Centro Cultural Metropolitano Gabriela Mistral durante el Gobierno de Salvador Allende Gossens), ha declarado que, por fuentes cercanas, "supo" que al momento del incendio y derrumbe de una parte del Edificio en marzo del 2006, el público apostado alrededor irrumpió en aplausos. Asimismo, tuvimos la oportunidad de entrevistar al vicepresidente de la CORMU durante el gobierno de la UP, el arquitecto Jorge Wong, consultándole por el mismo hecho:

Arq. Jorge Wong: Mire, como esta obra fue tan famosa... ¡Oiga! y yo vi en la tele cómo se cayó la estructura, me dio mucha pena. Ahora, Miguel me cuenta, de que él vino para acá cuando se produjo la caída de esto y dice que había mucha gente al lado de acá de la vereda, mucha gente y cuando se cae la estructura, la gente empieza aplaudir. Entonces, qué raro le dije yo ¿qué aplaudían? La versión de Miguel, porque yo no estaba aquí, es que la gente aplaudió porque ese edificio, cuando vino el golpe ahí se instaló Pinochet, y ahí tenía la sede de gobierno, estaba aquí, en ese edificio y que se quemara era como que se quemara la presidencia de Pinochet, y eso era lo que aplaudía la gente. Esa es la versión de Miguel, ahora no sé si será así o no, o estaban aplaudiendo la obra que había hecho Allende, no sé qué era lo que aplaudían. Entonces, yo más bien creo, fíjese, que aplaudían como eso fue la sede de gobierno de Pinochet era eso lo que estaban aplaudiendo como se estaba quemando. Porque siempre este edificio tuvo el apoyo de la gente, lo querían mucho, se creó un restaurant inmenso y ahí se hacía comida, con un chef español, excelente, muy de izquierda y la gente venía almorzar, porque era barato y muy bueno, entonces se hacían turnos porque la gente no cabía, entonces la gente se acuerda de eso y quiere al edificio. $^{25}$

¿Realmente la gente recordó a la UP? ¿Qué significaron los aplausos? Si nos detenemos en sus declaraciones, a pesar de las imprecisiones que fabulan el mito, se puede observar, por ejemplo, en su argumento una ambivalencia que busca manifestar una autoafirmación, casi como un consuelo: pese a que la gente asocia al edificio Diego Portales con la figura de Pinochet, de todos modos tuvo "el apoyo de la gente", "lo querían mucho", "la gente se acuerda de eso y quiere al edificio". Por el contrario, uno de los arquitectos que construyó el edificio, José Covacevich, indica que el edificio durante la UP tuvo sus defensores y detractores, incluso antes que fuera sede del régimen militar.

Luis Hernán Errázuriz y Gonzalo Leiva Quijada nos recuerdan que los regímenes autoritarios no solo dejan marcas en el mundo político o económico en el que intervienen, sino que también "impactan", en lo que los autores consideran "la dimensión estética y

fue convertido en Centro Cultural. Los otros integrantes del equipo de arquitectos fueron Hugo Gaffiero, José Medina, Juan Echeñique y Sergio González.

${ }^{24}$ La Corporación de Mejoramiento Urbano fue una empresa autónoma del Estado (1966-1976) tuvo como funciones mejorar y renovar las áreas deterioradas de las ciudades, mediante la aplicación de programas de rehabilitación y desarrollo urbano. Para ampliar información sobre CORMU ver Raposo, A., Valencia, M., \& Raposo, G. La interpretación de la Arquitectura. Historia de las realizaciones habitacionales de la Corporación de Mejoramiento Urbano CORMU en Santiago, 1966-1976. Santiago: LOM. 2005

${ }^{25}$ Entrevista realizada por Elías Sánchez a Jorge Wong en diciembre del 2014 


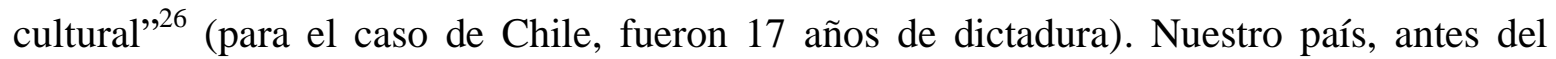
golpe de Estado venía de un proyecto político cultural de izquierda criollo (la vía chilena al socialismo $)^{27}$, en el cual se enmarcó la construcción de los edificios para la UNCTAD III.

En ese entonces (1970-1973), Chile no contaba, ni con la infraestructura, ni con los adelantos edilicios que le permitieran en menos de 3 años realizar una construcción como la que solicitó la $\mathrm{ONU}^{28}$. Pese a esto, y aquí comienza el relato épico, lo lograron. Se tomó el "desafió" (primera figura importante del relato), se presentó el "obstáculo" a vencer y los valores éticos y morales que movilizaron a las fuerzas: "la redención del Tercer Mundo", "la vía chilena al socialismo", "la imagen de Chile al mundo". Por otro lado, los héroes, Salvador Allende, sus colaboradores (arquitectos, ingenieros, artistas y artesanos) y "los trabajadores de la construcción" que tomaron en sus hombros el desafío para demostrar que se podía realizar la «Tercera Conferencia de Las Naciones Unidas sobre Comercio y Desarrollo» en Chile entre el 13 de abril y junio de 1972:

Salvador Allende (1972): "La gran tarea de UNCTAD sólo podremos realizarla con la movilización consciente de Chile, sus trabajadores y su pueblo, y yo sé que estaremos a la altura de la tarea histórica que hemos echado sobre nuestros hombros. Agradecemos la confianza que nos otorga la comunidad internacional y seremos dignos de ella"29

\footnotetext{
26 “Aunque se ha investigado el régimen militar (1973-1989) desde el punto de vista político, jurídico y económico, y a pesar de que existen estudios respecto de sus consecuencias en el campo de las artes visuales, no hay investigaciones que registren de manera sistemática las fracturas culturales provocadas por el disciplinamiento militar en Chile. Más deficitario aún es el trabajo sobre las manifestaciones culturales promovidas por el régimen; muchas de las cuales no estuvieron necesariamente coordinadas o reguladas de un modo centralizado". Errázuriz, Luis Hernán; Leiva Quijada, Gonzalo. El Golpe Estético, Dictadura Militar en Chile, 1973-1989. Santiago de Chile: Editorial Ocho Libros. 2011., p.7

${ }^{27}$ Esta vía se caracterizó por ser, un camino democrático al socialismo.

${ }^{28}$ Como indica uno de los documentos redactados por el Presidente de la Comisión para la UNCTAD III Felipe Herrera en donde detalla los requisitos constructivos y de conectividad que debía tener los inmuebles solicitados para la UNCTAD III y los plazos: "La Tercera Conferencia para el Desarrollo y Comercio de las Naciones Unidas debe iniciarse impostergablemente a comienzo de abril de 1972. El programa definitivo fue elaborado en Abril de 1971, lo que determinaba un plazo fijo de proyecto y construcción de 11 meses. El programa para UNCTAD III demanda la construcción de: una sala de reuniones plenarias con capacidad para 2000 personas; dos salas con capacidad para 500 personas cada una; dos salas con capacidad para 250 personas cada una y tres salas para 100 personas; cuatro salas para 20 a 40 personas; restaurant autoservicio para 600 personas; cafetería para 200 personas; tiendas, agencias de Banco y Viajes; oficinas para correos, telégrafos, telex, cables y teléfonos; salón de delegados; servicios de traducción simultánea para todas las salas, y espacio de oficinas para 1000 funcionarios. A este programa se agregó estacionamiento para 250 vehículos en subterráneo dada la ubicación del terreno y su uso futuro". En Herrera, Felipe. Edificio sede para UNCTAD III. Centro Cultural Metropolitano de Santiago. Biblioteca Nacional, sección chilena. 1972 , p.4

${ }^{29}$ Boletín 65, Comisión Chilena UNCTAD III. Editorial Quimantú: Santiago de Chile, 1972. Biblioteca Nacional, sección chilena., p. 2
} 
La importancia de esta conferencia radicó, en primer lugar, en la posibilidad de discutir e instalar una crítica que permitiera romper con las estructuras y circuitos comerciales que mantenían a América Latina, Asia y África en el subdesarrollo ${ }^{30}$.

Considerando la política económica que tomó Chile durante el Gobierno de Salvador Allende, la Conferencia le permitió defender el ejercicio soberano de disponer de los recursos naturales que estaban en manos extranjeras y lograr legitimidad internacional en la materia ${ }^{31}$. En segundo lugar, le permitió encarar varios desafíos durante su Gobierno. Retos que iban desde mantener el pacto dentro de la misma izquierda y sectores populares que lo apoyaron, responder a las expectativas del mundo obrero-popular; confrontar a la derecha chilena y a la parte más conservadora de la Democracia Cristiana (DC), sumado a la "campaña del terror" orquestada desde EEUU y sus organismos de inteligencia.

La realización de la UNCTAD III le permitió mostrar el país al mundo y su propuesta para América Latina. Pero antes, había que construir la infraestructura necesaria para la Conferencia. Construcción que duró 275 días, donde se hicieron turnos de día y de noche, participando arquitectos, ingenieros, trabajadores de la construcción, empresas privadas y públicas, artistas, brigadistas, militares y políticos de centro-derecha e izquierda. Sin embargo, con el golpe de Estado el 11 de septiembre de 1973, las FFAA comienzan una política de limpieza y depuración de los símbolos de izquierda o que remitieran al universo ideológico de la UP, poniendo fin a la experiencia de la Unidad Popular y del Centro Cultural Metropolitano Gabriela Mistral:

El edificio Diego Portales constituye un legado tangible de transformaciones y mutilaciones político-culturales. Con la instalación de la junta militar se erradica cualquier vestigio que recordara el espíritu original del edificio, que era ser sede de la cultura y el intercambio ciudadano. Las obras de arte y los objetos retirados durante dictadura correspondían, de hecho, a la estética de la Unidad Popular (...) el

\footnotetext{
${ }^{30}$ Como lo explica un documento de la Comisión chilena para la UNCTAD III: "La PRIMERA UNCTAD se realizó en Ginebra y en 1964 y fue propuesta a las Naciones Unidas por los países en desarrollo. Se plateó esta reunión a la comunidad internacional a fin de modificar los principios y las normas que rigen el comercio internacional, que otorgan un trato preferencial a los países desarrollados, en perjuicio de los países en desarrollo. De esta Conferencia puede señalarse tres aspectos positivos: la UNCTAD se estableció como órgano permanente de la Asamblea General de las Naciones Unidas; se reconoció a nivel mundial la injusticia que implicaba la estructura del comercio internacional; y hubo acuerdo en señalar cuáles eran las medidas que debieran tomarse para lograr el desarrollo económico, la paz y la prosperidad." Román, Silva. El Tercer Mundo, UNCTAD III y Los Trabajadores. Comisión chilena para la UNCTAD III. Biblioteca Nacional, sección chilena: Santiago, 1972., p.11

${ }^{31}$ Esto queda de relieve en el tono de los documentos de la Comisión chilena para la UNCTAD III y las gestiones políticas del Ministro del exterior Clodomiro Almeyda, que en la reunión del GRUPO DE LOS 77 del Tercer Mundo (Lima, octubre y noviembre de 1971), buscó armonizar posiciones de cara a la celebración de la UNCTAD III en Santiago de Chile: “(...) En la reunión de Lima se aprobó como una de las principales resoluciones un nuevo principio general de UNCTAD, presentado por la Delegación de Chile. Señala este principio: Cualquier presión política o económica externa destinada a coartar el pleno ejercicio del derecho soberano que tiene cada país de disponer libremente de sus recursos naturales, en provecho del desarrollo económico y del bienestar de su propio pueblo, viola los principios de la autodeterminación de los pueblos y de no intervención y, constituye una agresión económica al país afectado por ella". Silva, op. cit., p.12
} 
régimen militar, desde aquella "torre de gobierno" que reemplazó a La Moneda, se preocupó de establecer simbólicamente una imagen de poder acorde con la sensibilidad castrense, erradicando parte no despreciable de su patrimonio artístico y alterando su concepción arquitectónica. De esta forma, hizo desaparecer obras de arte e instaló bustos de héroes patrios, negó el acceso de la ciudadanía por medio de rejas, creó barreras físicas claras y disuasivas y próceres; es decir, realizó un golpe estético claro y contundente. ${ }^{32}$

Destruido el Palacio de La Moneda, la Junta Militar se ubicó en el Centro Cultural Metropolitano Gabriela Mistral. Al clausurar su función pública y cultural, el complejo arquitectónico cambio de nombre, función y forma. A través de la figura del prócer se trató de legitimar su "segunda independencia", 33 como heredera del "legado histórico portaliano": una República autoritaria ${ }^{34}$. En definitiva, la mayoría de las obras, esculturas y terminaciones que hicieron a este complejo un promotor de las artes, de la cultura y la sociabilidad, fueron destruidas o repintadas como acto purificador ${ }^{35}$. El famoso Casino, que se transformó en centro social del gobierno de la UP, desapareció, como todos los dispositivos que relataron la participación obrera, profesional y artística en la construcción del complejo arquitectónico. Así, Gabriela Mistral, Salvador Allende, los trabajadores, los artistas y los profesionales pasaron a un olvido política y militarmente construido durante 17 años de dictadura. Como consecuencia, el edificio Diego Portales terminó siendo asociado a la figura de Augusto Pinochet, contaminando con ello no solo la figura de Portales, sino que toda la historia del complejo edilicio.

Estos hechos, denominaciones u homologaciones, son la base de los sentidos comunes que cargan de gravedad a este complejo arquitectónico. En específico, la placa geológica de la dictadura militar que tiende a eclipsar los estratos anteriores al Edificio Diego Portales. Esta simetría logra un equilibro al momento del incendio, permitiendo que estos relatos subterráneos cobren notoriedad y empiecen a disputar el sentido de los hechos y las huellas que representan sus experiencias. Por lo mismo, los relatos de los arquitectos y trabajadores de la construcción, nos narran y presentan otro marco social de la memoria,

\footnotetext{
${ }^{32}$ Errázuriz, H.; Leiva, G. op. cit., pp.95-97

33 La dictadura militar también construyo representaciones del pasado que rescataron y crearon mitos republicanos para legitimar sus acciones. El mito de la segunda independencia, según el estudio cultural que realizó Isabel Jara Hinojosa (2011), significó un “(...) relato inaugural cargado de emotividad, que suministraba sostén, aglutinación y adaptación sociológica y psicológica ante la nueva realidad política. Dado que el régimen no podía reconocerse haciéndose a sí mismo -auto instituyendo e imponiéndose por la fuerza, este mito fue enfático en resaltar el origen ciudadano del golpe y su dilatada genealogía, remontable a la independencia decimonónica". Jara Hinojosa, Isabel. Graficar una "segunda independencia": El régimen militar chileno y las ilustraciones de la Editorial Nacional Gabriela Mistral. Historia No 44, Vol. I, Santiago de Chile, enero-junio: 2011 pp. 131-163 http://www.scielo.cl/scielo.php?script=sci_arttext\&pid=S071771942011000100004

34 Jara Hinojosa, Isabel, Op., Cit., p. 132

35 Según Hinojosa (2011), la purificación durante el régimen, consistió en raspar y repintar murales, retirar monumentos o símbolos alegóricos a la UP, como una acción político-represiva que buscó formalizar a la población. Recordemos que uno de los eslóganes de la UP era la fiesta que significó el triunfo de Salvador Allende y su revolución de empanada y vino tinto.
} 
que resalta la experiencia constructiva y política de la celebración de la UNCTAD III y del Centro Cultural Metropolitano Gabriela Mistral que estuvo en la subterraneidad por más de 35 años.

Si retomamos el testimonio de Jorge Wong podemos observar la utilización de adverbios como el "muy" para manifestar atributos, que destaquen esta obra no sólo arquitectónica, sino también social y política en la época de la UP. Con esto, no queremos decir que el testimonio de Jorge Wong o el de Miguel Lawner sean falsos, por el contrario, buscan contarnos una historia, que al mismo tiempo es su historia y que se enfrenta a un imaginario superior, oficial, que asocia esta obra con un régimen militar y con el mismísimo dictador.

Mientras algunas publicaciones, durante el 2007 y 2009, tiende a desmitificar los edificios, como una forma de exculpar sus muros, ya que "son mudos testigos de la historia" ${ }^{36}$, nuestros protagonistas nos introducen en un estrato intensamente recordado. La intemporalidad de su voz da cuenta de un tiempo en latencia, de cómo se encuentran absorbidos por los acontecimientos. "Que la historia se cuente bien contada", si tomamos esta frase de Covacevic y nos hacemos del argumento de Portelli (2004), con el incendio del Edificio Diego Portales y con los aplausos, se consolidó parcialmente "un sentido común empapado de desinformación". Con esto queremos decir, que con la reconversión del edificio Diego Portales a Centro Cultural Gabriela Mistral, no se buscó adjudicar responsabilidades, ni realizar juicios en torno a las experiencias ahí acaecidas. No se quiso esclarecer cómo se lo apropiaron las Fuerzas Armadas, ni qué hicieron con las obras de arte y esculturas que eran patrimonio de la Nación.

Mucho menos relatar y representar la historia del imaginario urbano y político que la UP plasmó con su construcción. Entonces, ¿por qué esperar que la ciudadanía supiera el valor arquitectónico, patrimonial que hizo de este edificio un emblema del Gobierno de Salvador Allende? La memoria de la UP se encuentra envenenada producto de las acciones castrenses, que buscaron "extirpar" de la sociedad los vestigios de esta experiencia. De ahí que los relatos de nuestros protagonistas generen otro efecto explicativo, puesto que están haciendo una defensa de sí mismos; al mismo tiempo que buscan contarnos su historia y se van haciendo conscientes de su papel, en un hecho intensamente interrogado producto del incendio. En suma, el público aplaudió el desplome del edificio porque representó la dictadura militar, es la imagen que prevaleció durante la post-dictadura.

Sumemos otro hecho. En diciembre del 2006 fue la muerte de Augusto Pinochet y pese a toda la información que circuló durante el año, relatando la procedencia del GAM, gran parte de la ciudadanía se sacó fotos frente al Edificio Diego Portales (que estaba en

\footnotetext{
${ }^{36}$ Nos referimos, en primer lugar, a la sección de Javier Rojahelis, columnista del diario El Mercurio en su sección de Arquitectura, que compiló los testimonios de varios arquitectos para realizar un "JUICIO al edificio Diego Portales ¿Salvarlo o Reemplazarlo?”, nombre con el que abrió la edición de Artes y Letras del periódico el 12 de agosto de 2007. En segundo lugar, la propuesta de Carrasco y los demás autores del libro «Trabajo en Utopía. Monumentalidad arquitectónica en el Chile de la Unidad Popular». En Gonzalo Carrasco. Blanqueando, borrando, cubriendo: el edificio del UNCTAD III y las evidencias de un tiempo fracturado. En Matías Allende \& Carol Illanes (Comps.), Trabajo en Utopía. Monumentalidad arquitectónica en el Chile de la Unidad Popular, Santiago de Chile: Adrede editora, 2014.
} 
proceso de demolición), para celebrar la muerte del dictador en las mismas escalinatas donde éste había dado sus discursos (ver fig. 1 y 2$)^{37}$.

Fig. 1: Pinochet en un acto público en el frontis del Edificio Diego Portales. ${ }^{38}$

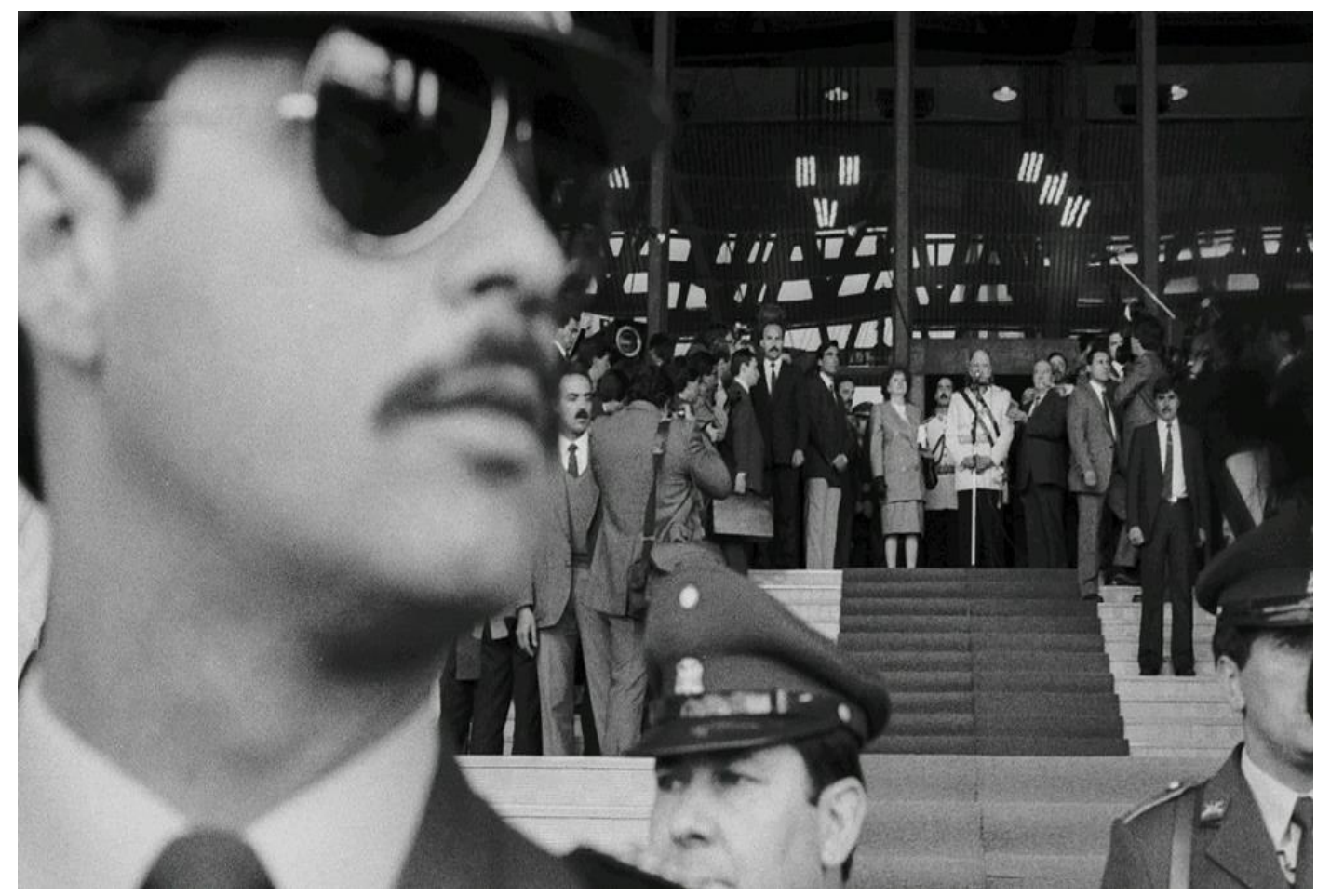

Al respecto, Michael Löwy (2003) subrayó que los juicios de la historia no son absolutos, ni definitivos. Por el contrario, son relatos en constante re-elaboración, puesto que el porvenir logra reabrir hechos históricos que se consideraban cerrados, permitiendo "rehabilitar" no sólo investigaciones, hipótesis o tesis, sino también a víctimas calumniadas, reactualizar esperanzas y aspiraciones vencidas, redescubrir combates olvidados o juzgados "utópicos", "anacrónicos" y "a contrapelo del progreso"39. En definitiva, con toda la información y gestión que hoy realiza el GAM como espacio de memoria y Centro Cultural, podemos estar seguros que los aplausos no volverían a ocurrir. La UP sólo alcanzo a durar 3 años, 1000 días. Mientras que la dictadura militar 17 años,

\footnotetext{
${ }^{37}$ La muerte de Pinochet fue el 10 de diciembre del 2006.

${ }^{38}$ Foto celebración aniversario Constitución de 1980 (11 de Sep. 1988). Fotografía de Anselmo Córdova. Imagen seleccionada por Bruno Salas a partir de una entrevista que le realizó Roberto Doveris sobre su Documental Escapes de Gas, que cuenta la historia del Edificio con material audiovisual inédito (2015). http://www.cinemachile.cl/bruno-salas-estrena-su-documental-escapes-de-gas-en-salas-nacionales/

${ }^{39}$ Löwy, Michael, Walter Benjamin: aviso de incendio, Una lectura de las tesis "sobre el concepto de historia”, Buenos Aires: FCE, 2003, p.183
} 
más 16 años de silencio en post-dictadura. El retorno del pasado es inevitable, en casi todos los países que han vivido hechos violentos, el pasado retornó y obligó a ocuparse de estos sucesos. Veremos con la distancia temporal y las acciones culturales que se están realizando en Chile, como poco a poco se va rehabilitando no sólo víctimas, sino aspiraciones y combates olvidados de la historia.

Fig. 2: Celebración muerte de Pinochet en el frontis del Edificio Diego Portales en diciembre del 2006 . $^{40}$

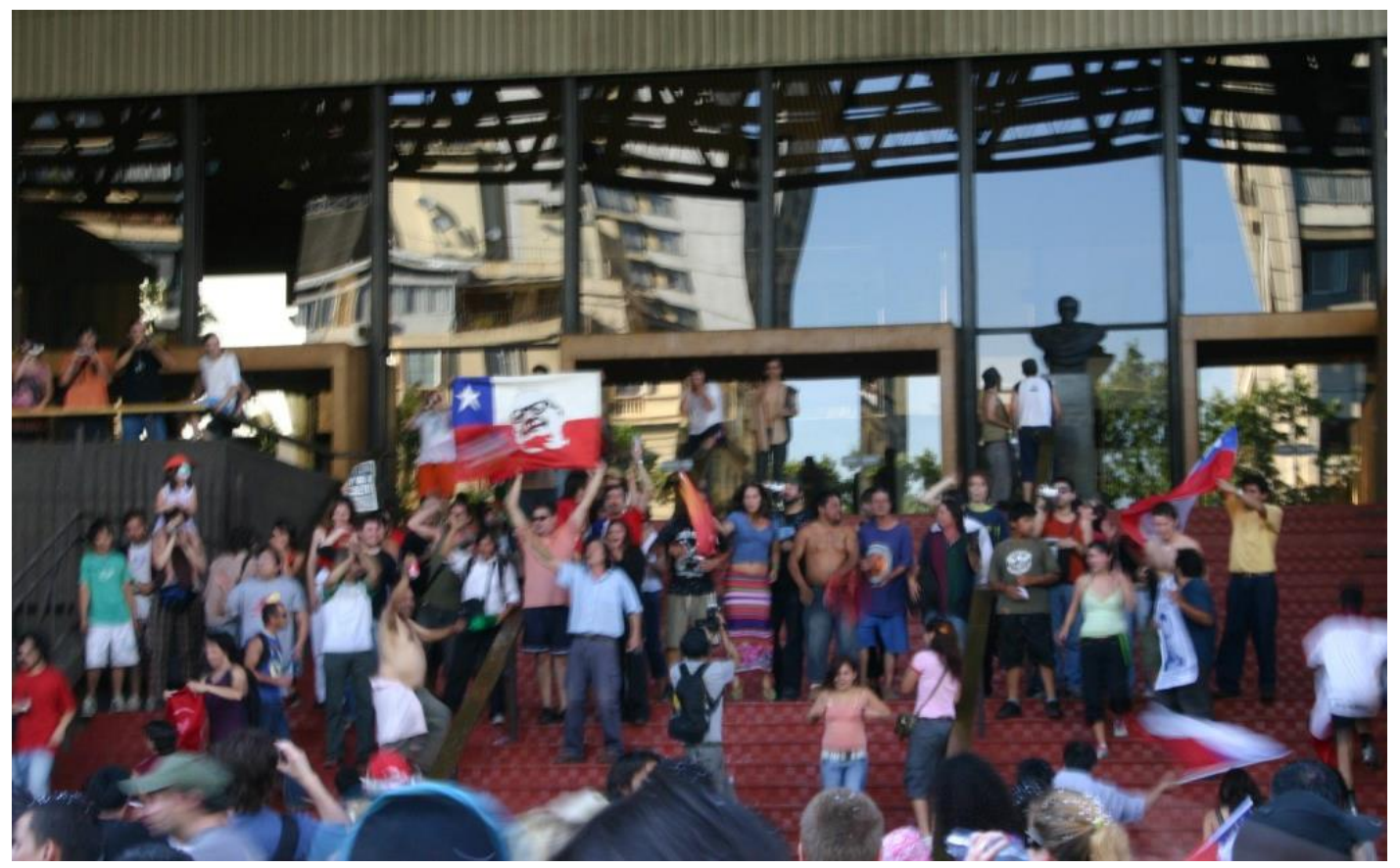

\section{Mito y memoria en la trama oral de los vencidos}

Para Alessandro Portelli (2016), el mito no es un relato falso del cual debamos alejarnos por parecer un cuento inventado. Por el contrario, nuestra tarea es dilucidar que acontecimientos o serie de ellos son extendidos simbólicamente, ¿Por qué y qué formas narrativas adquieren? Para nuestro caso, el mito político, toma tintes épicos (propio del relato militante) y trágicos producto del choque de dos experiencias antagónicas: la UP y la dictadura $^{41}$. Es importante señalar que el "mito", como relato, como creación, en una

\footnotetext{
${ }^{40}$ Autoría desconocida, fuente: http://flickrhivemind.net/Tags/diciembre,pinochet/Interesting

${ }^{41}$ La tragedia representa dos derechos rivales que se disputan el espacio y el tiempo, dos principios morales que se traban en lucha para determinar cuál puede ser la forma de la vida humana en una encarnación social específica. Para Hayden White: “(...) En la tragedia (...) hay intimaciones de estados de división entre hombres más terribles que el que incito el agón trágico al comienzo del drama. Sin embargo, la caída del protagonista y la conmoción del mundo en que habita que ocurren al final de la obra trágica no son vistas como totalmente amenazantes para quienes sobreviven a la prueba agónica. Para los espectadores de la
} 
acepción simple, puede ser entendido como cohesionador social, puede estar referido a eventos históricos, políticos, ideológicos, puede dar cuenta de héroes, orígenes, transiciones, fundaciones, etc. Como símbolo ${ }^{42}$ tiene una potencialidad que el discurso de la historia más tradicional y positivista rechaza: por considerar estos relatos alejados de la "verdad", menosprecia las emociones, por lo tanto relativiza las afectaciones -las formas como se inscribe la memoria-, vale decir, menosprecia la cualidad de los hechos y la forma como se transmiten. ${ }^{43}$

Asimismo, los mitos también pueden ser instrumentos del poder y convertirse en formas ideológicas de manejar la historia, a partir de estereotipos, sentidos comunes, que viniendo desde arriba tienden a tergiversar, avergonzar y criminalizar identidades sociales. En definitiva, un sinfín de cualidades hace del mito un relato interesante de analizar, aunque nos debemos cuidar de verlos sólo como un vestigio de sucesos que pasaron. Puesto que, por un lado, los mitos como forma de tramar, de contar una historia, tienden a inmovilizar sucesos, que son constantemente "re-elaborados", de ahí que el mito se acerque más a la memoria, entendida como elaboración presente de un pasado ausente. Por otro lado, según Rabotnikof debemos realizar dos recaudos metodológicos. El primero, es que las reflexiones en torno al mito político deben estar enfocadas en ejemplos concretos: "(...) Ello hace que las teorías generales, la del mito como instrumento de dominación (En Cassirer) o, por el contrario, como medio de liberación de una clase (en Sorel o en Gramsci) siguen ligadas a sus condiciones y modelos iniciales (Bottici, 2006: 317)"44. Por otro lado, el ámbito en que se juega la políticidad del mito y la memoria, no está en su contenido, sino en “(...) la relación entre una narrativa y su capacidad de politizar las condiciones de vida de un grupo" 45 .

Teniendo en consideración este último elemento, como lo afirma Frank Ankersmit (2008), nuestro mito político se encuentra en un punto intermedio, entre la memoria y el olvido. Para este historiador, en casos violentos como dictaduras, genocidios, masacres, etc., más que "cohesionador social", nos representa una "transición", convirtiéndose en un relato que da cuenta de una perdida ${ }^{46}$. Así, estos relatos tienen la potencialidad contenida de la tormenta del cambio histórico. Nos encontramos con narradores cuya percepción se detiene en momentos importantes de su vida, siendo absorbidos totalmente por el acontecimiento, por lo que estaba en juego. Como consecuencia, la forma de ordenar su relato y su tono serán perspectivas desde las cuales se posiciona en esta lucha de clases cultural. Perspectivas que se relacionan para darnos relatos "en primera persona", donde la

contienda ha habido una ganancia de conciencia. Y se considera que esa ganancia consiste en la epifanía de la ley que gobierna la existencia humana, provocada por los esfuerzos del protagonista contra el mundo. Hayden White, Metahistoria, La imaginación histórica en la Europa del Siglo XIX, D.F. México: FCE, 1992, p., 20

${ }^{42}$ Para analizar más detalladamente el fundamento histórico del mito ver Barthes, Roland. Mitologías. España, Siglo XXI editores. 1999.

${ }^{43}$ Gustavo, Becerra \& Nancy Rocío, "Mito e historia", Revista Vínculos, V. 11 número 1, Revista distrital Francisco José de Caldas, Colombia: 2014, pp. 221-232

${ }^{44}$ Rabotnikof. Op. cit., p.113

${ }^{45}$ Op. cit., p. 114

${ }^{46}$ Frank Ankersmit, Experiencia histórica sublime, Santiago de Chile: Palinodia, 2008. 
“invención” y la "información” se conjugan en formas expresivas que pueden absorber al narrador (la épica o la tragedia) o tomar distancia de él mismo (ironía).

Para una identidad que se forjó en una tradición política de izquierda y en relación a ello construyó su autoestima e imaginario, perder los lugares físicos o los espacios político militantes, abonan a la perdida de prestigio. Como punto de partida, podemos afirmar que esta situación obligó a intentar recuperar el lugar y el sentido que tuvo este complejo arquitectónico en un pasado más lejano, para reconectarlo con el presente de su reconversión en Centro Cultural entre el 2006 y 2010. De esta forma, relatos absorbidos por el acontecimiento histórico, cobraron notoriedad y se vehiculizaron como representaciones del pasado:

Manuel Bustamante (Obrero) ${ }^{47}$ : “(...) Había que empezar a hacer todo lo que se llamaba la instalación de agua potable, así que el trabajo fue infinito, pero lo hicimos con un cariño y un sacrificio, porque era muy normal que llegaba el Presidente de la República y le daba la mano al compañero trabajador diciendo: “¿cómo estamos aquí? ¿Salimos?”. Y contestábamos: "bien compañero, salimos adelante". En una ocasión estábamos colocando artefactos cuando me encuentro con el compañero Ministro José Toha dándonos la mano, sin ninguna diferencia de nada, sino que era una cosa tan bonita la forma en que se trabajaba con ellos, que daba gusto salir con esa obra (...) le pusimos un empeño y trabajamos hasta que nos sentimos orgullosos y todavía cuando paso por ahí, esa obra me da una pena, una impotencia de verla, sobre todo cuando no se fue capaz - porque esto yo se lo saco a la CONCERTACIÓN-, de haberle hecho un trabajo de mantención porque producto de eso fueron los incendios que se produjeron ahí. Y de verla ahora después, como que da pena y rabia, la miramos y decimos: "tanto que trabajamos en esta obra". Porque era un edificio simbólico; yo creo que no hay ningún otro que se haya construido en el tiempo record que se construyó ese edificio y más para el significado que tenía en el gobierno de nuestro compañero Presidente. La verdad es que me emocionó mucho a veces conversar estas cosas porque uno se relacionó con tantos compañeros trabajadores que habíamos ahí, de todas las áreas, de todas las especialidades: concreteros, enfierradores, soldadores, estucadores, en fin y todos le poníamos empeño, ahí no había nada de diferencia, que estamos mal pagados (...) ¡No! Aquí le echamos pa’ delante no más y sin pensar en precio. Porque aquí a esta obra hay que sacarla pa' adelante. Yo era presidente en el sindicato, así que decía: "aquí no me vengan con cuentos, porque esto tenemos que sacarlo a como dé lugar". Y así lo hicimos, compañero, con bastante orgullo. Esa es la herencia que yo llevo hasta estos años y no la voy a olvidar nunca" ${ }^{48}$.

El relato de Manuel Bustamante, da cuenta de un pasado mítico, con un mensaje, una ganancia de conciencia, de la emoción de un narrador que participó en la historia y que a su vez, da cuenta de cómo esta lo afectó. Estas experiencias se componen de mitos que generan un tiempo especial, en donde los acontecimientos son narrados de otra forma,

${ }^{47}$ Gasfíter / plomero en el edificio de la UNCTAD III durante 1971-1972.

${ }^{48}$ Paulina Varas \& José Llano. Op. cit., p. 60 
sacándolos de la cronología ordinaria en la que se mueven periódicos o la propia historiografía ${ }^{49}$ :

Eduardo Guerra (obrero $)^{50}$ : “(...) yo recuerdo que incluso cuando terminé mi trabajo me enfermé porque estuve tres días y noches sin dormir. Me sentí totalmente comprometido con mi trabajo porque siempre he sido un hombre de izquierda y consideraba que con este trabajo estaba apoyando a mi Gobierno, al que había estado tratando de sacar desde 1952, desde la primera proclamación de Allende en Valparaíso donde yo estaba en ese momento presente... Recuerdo que uno de los compromisos de los artistas fue el que no se firmaran las obras con los nombres; a mí me dijeron que si uno de ellos firmaba yo debía poner mi nombre abajo. Recuerdo que solo uno de ellos lo hizo, pero yo no quise poner mi nombre allí. La razón es que se trataba de una fuerza común, y no del nombre de una persona. Para mí todo este trabajo significó un compromiso con mi Presidente, yo creía en lo que allí se estaba haciendo. Fui militante desde joven en las Juventudes Comunistas. Hoy tengo 86 años y desde los 21 años estuve vinculado a movimientos sindicales. Cuando viví en Valparaíso trabajaba como mueblista y además estudiaba en la noche en la Universidad Técnica Federico Santa María la carrera de Dibujo de Muebles. Luego en Santiago me independicé y tuve mi taller... Yo me sentía orgulloso del trabajo que realicé. Me sentía satisfecho, pero para mí no era algo para querer resaltar, ya que incluso mucha gente no supo que yo hice este trabajo. Aunque conservé el contrato de confección de obra que firme con la Comisión Chilena de la UNCTAD en abril de 1972 con el General Orlando Urbina y otro contrato con don Felipe Herrera. Y además, el presupuesto... Hoy, con este material y con los planos que conservo se podrían rehacer muchas de las obras desaparecidas. Para mí, todo esto es importante aún. La prueba es que sigo guardando todas estas cosas"

Si observamos los testimonios, tener abierta la herida se transformó en un deber de memoria ante los usos y olvidos de la Historia. Garantizar el recuerdo como refugio de dignidad, es también la posibilidad de recobrar no solo la autoestima, sino la posibilidad de conocimiento. La herida reclama su protagonismo hoy, fue la que resistió los embates, la colisión de las fuerzas y el castigo que le fue impuesto.

No es fácil establecer porque molesta, por un lado, tanto un pasado que es relatado de forma épica y mítica y, por otro lado, la molestia de los protagonistas de esta historia por estos "olvidos" e invisibilizaciones sufridas. Nora Rabotnikof nos da algunas pistas para entenderlo: "Tal vez la dificultad de los mitos políticos en nuestro presente no se deba (sólo) al aprendizaje político de las sociedades, o al desencantamiento del mundo o al triunfo de la racionalización (o de la razonabilidad) en política, sino a esa imposibilidad de volver a sentirnos herederos de un pasado y forjadores de un futuro". 52

Lucha de fuerzas, que se confrontaron no solo en el campo político y económico, sino que en el simbólico, en el tiempo latente, en el devenir frustrado, de ahí la idea de lucha cultural por el significado de los hechos. Donde la elección, la ordenación de la serie

\footnotetext{
${ }^{49}$ Portelli, op. cit. 2016

${ }^{50}$ Carpintero y artista encargado de los marcos realizados a la mayoría de obras de arte que acompañaron la estructura del edificio de la UNCTAD III durante 1971-1973.

${ }^{51}$ Paulina Varas \& José Llano. Op. cit.

${ }^{52}$ Rabotnikof., op. cit., p.122
} 
de acontecimientos, donde los protagonistas buscan ubicarse, generando una crítica ética desde su visión y posición, como Eduardo Guerra que estuvo con el héroe "desde su primera proclamación" o estar con él en el momento que se desató el agón en esta disputa de fuerzas, donde la épica de la lucha de la UP es el enaltecimiento del significado de su aporte a esta historia más general. Episodio negado, aporte frustrado como podemos observar en el relato del escultor y artista Federico Assler:

Federico Assler (artista escultor) ${ }^{53}$ : "Yo creo que nunca después de la realización tanto del edificio como la torre se vio esta participación de tantos artistas. Creo que nunca después se ha realizado algo parecido a lo que sucedió en la construcción de este edificio, porque trabajábamos con un entusiasmo realmente muy impresionante, tanto los arquitectos, como los trabajadores y los artistas que realizaron obras incorporadas tanto del edificio como en el exterior. Fue un momento muy especial. Nunca se le había encargado a tantos artistas colaborar al mismo tiempo con obras de arte, mientras se construía el edificio de la UNCTAD III. Todos trabajamos con un tremendo entusiasmo y contra el tiempo. En el caso de mi obra fue el afán de incorporar la escultura en el espacio público, en la calle misma. Ir con mi obra al encuentro del hombre ese era el objetivo. Crear una plaza escultórica (...) en el fondo así fue pensada con ese espíritu del momento y como una conmemoración del acontecimiento e inauguración internacional del Edificio UNCTAD III. Desgraciadamente eso se logró durante solo un año y medio, y luego vino el Golpe Militar y $¡$ ha estado encerrada desde el 11 de septiembre del 73 hasta hoy día! ${ }^{54}$.

La tragedia como modo de argumentar, logra un efecto explicativo que da cuenta, no sólo de cómo los protagonistas se han consumido en el proceso posterior a la derrota, sino también cómo desde la posición de vencidos, lograron una ganancia de conciencia a costa de una sombría resignación. Finalmente, lo que sucedió con el GAM para estos artistas, arquitectos y obreros fue una extensión de lo ocurrido con el bombardeo al Palacio de La Moneda y la muerte de Salvador Allende: se perdieron a sí mismos en la agonía y el agravio a la identidad que habían construido en el período previo al 11 de septiembre:

“(...) el tipo de trauma que siempre llevaremos con nosotros después que la Historia nos ha forzado a enfrentarlo; es un trauma para el cual no se ha encontrado cura. La nueva identidad es principalmente constituida por el trauma de perder la identidad anterior (...) Y entonces el trauma es tan permanente como lo es la pérdida de la identidad previa. De ahí que podamos decir que nuestra identidad colectiva es la suma de todas las cicatrices en nuestra alma colectiva, cicatrices que ocasionaron el forzoso abandono de identidades anteriores, cicatrices que nunca nos abandonarán completamente y que nos causarán un dolor continuo y mantenido" $" 55$.

\footnotetext{
${ }^{53}$ Federico Assler escultor chileno premio nacional de artes en el 2009. Es especialista en obras escultóricas enfocadas en el espacio público, de ahí que su trabajo acompañara la estructura del edificio de la UNCTAD III y Centro Cultural durante 1971-1973.

${ }^{54}$ Paulina Varas \& José Llano. Op. cit., pp. 59-60

${ }^{55}$ Ankersmit, op. cit., p. 119
} 
En sus relatos observamos cómo se sobreponen distintos eventos, la construcción del edificio, resaltando las figuras heroicas con las cuales se relacionaron. Relación "sin distancias" con Salvador Allende y el Ministro José Tohá (éste último torturado y asesinado en dictadura en 1974). Su esfuerzo en la realización de la obra, lo que significó relacionarse con los otros actores al parecer disímiles en la cotidianeidad política del hoy, pero que en esa experiencia se posicionaron en un plano de horizontalidad. Las palabras emocionadas de Assler contienen un reclamo que puede ser extendido a los demás artistas y trabajadores que participaron de la construcción del GAM. Puesto que no sólo dejaron una pieza artística, sino que la impronta de un trabajo colectivo con mensaje futuro. La escultura de Assler fue recuperada y entre el 2012-2013 comenzó a ser restaurada y trasladada:

Federico Assler: “(...) Un momento de mucha alegría y esperanza, he esperado estos 41 años, hice esta obra cuando tenía 42 hoy tengo 84 años, miles de noches he pensado en esta obra, una obra que fue hecha justamente para incorporarla a la ciudad, al peatón, al ciudadano, una obra que siempre la pensé para que pudiese ser caminada, mirada, ocupada (...) Para mí que esto se incorpore a la calle es algo que he deseado la mitad de mi vida. Lo he soñado tantas veces..."

Pese a que se logró terminar con el régimen de Pinochet, el recorrido del GAM en la post dictadura se convierte en metáfora de la memoria de una parte de los vencidos. El largo camino se inició con su reconversión y los proyectos artísticos que buscan movilizar sus huellas y estratos. Si bien los tiempos cambiaron, de a poco el GAM va logrando movilizar sus huellas, pese a la cultural neoliberal imperante.

\section{Ideas finales}

"A las víctimas se les da una capacidad de profundidad de vista que los victoriosos nunca tienen. La historia los ha escogido a ellos para que hagan estos terribles poderes aparentes, $s u$ destino personal fue un emblema del curso de la historia del mundo -y han sentido todo el drama de ello casi con una intensidad existencialista" ${ }^{57}$

¿Qué hacer con los perfiles épicos que fueron apareciendo en los relatos de los protagonistas, en las imágenes desempolvadas que nos hablan de otra UP, alejada del desabastecimiento y del caos marxista? Algunos sostuvieron que había que desmitificar los edificios, alejarlos de utopías irrealizables, porque eran sólo "escenarios" y "mudos testigos de la historia".

En este aspecto, el incendio permitió recuperarlo, fue una victoria de la memoria. Sin embargo, la batalla continúa en torno a su re-utilización. La utilización de la memoria

\footnotetext{
56 Testimonio del escultor, consignado al momento de su re-inauguración por el equipo de plataforma urbana en octubre del 2013. http://www.plataformaurbana.cl/archive/2013/10/29/la-escultura-de-federico-assler-quehoy-volvio-a-ser-de-los-ciudadanos/

57 Ankersmit, op. cit., p. 175
} 
como señaló Todorov $^{58}$, tiene que ver más con el papel que desempeña en el presente y el porvenir, ahí podemos formular una pregunta ¿Qué papel juega el GAM en el presente y en el porvenir? En un primer momento, con el estallido del pasado, se permitió la elaboración del mismo; había un deber de los protagonistas por testimoniar la historia del gigante de hormigón durante la UP.

La trama de los vencidos, es distinta a las de las víctimas. El relato del vencido guarda una cualidad benjaminiana que debe ser tomada en consideración. Este es, el nivel de conciencia que tiene de los hechos históricos; las mejores reflexiones las podremos sacar siempre de los vencidos. En principio, todo comienza con esa atmósfera mítica que envuelve los hechos de la UP, vamos de la épica del triunfo y trabajo durante el gobierno popular a la tragedia que significó su fin y la dictadura militar. Es un relato dominante, en las que los distintos actores con los que hemos trabajado han organizado sus experiencias y las han transmitido, dando cuenta de lo que se ha perdido y ganado con el conflicto de dos fuerzas rivales.

¿Por qué molesta tanto el mito? Fue una de las preguntas que nos hicimos y que relacionamos con la molestia hacia la memoria. Una vez que entendamos la relación estrecha entre mito y memoria (relato y recuerdo), podremos destrabar esa tendencia, propia de occidente de alejarse de lo mítico, de alejarse de la memoria. Las memorias, se substraen del tiempo, no saben de cronologías lineales, se sedimentan en estratos que explotan, de ahí la potencialidad del mito en los estudios de memoria. Nos permite comprender la cualidad de los hechos, de los cambios históricos, de las transiciones, de las identidades destruidas, de los mundos que han desaparecido. Con la tendencia que enfrentamos de destrucción de huellas, los historiadores e investigadores del tiempo presente deben vigilar y analizar estos mitos antes de deslegitimarlos.

Sin ellos, ninguna piedra podría hablar. Saben los por qué, los cómo, los quiénes y los cuándo. Llevan las cicatrices, al igual que los edificios, que obligó el abandono de la identidad previa; muchos de ellos fueron cesanteados, sus obras y casas cayeron en manos castrenses, las transformaron, recalificaron y se entregaron a la tarea de criminalizar los valores que movilizaron a estos sujetos durante el período previo. Que distinta sería la historia del GAM si buscáramos desmitificar los edificios. No se trata de volver a la Unidad Popular o a la dictadura militar. Sostenemos más una formula como Todorov, en donde el pasado no debe regir el presente, pero si debemos esclarecerlo, aceptar responsabilidades, aciertos y generar un relato ejemplar. Sin embargo, aun el GAM es asociado a la dictadura militar y eso se debe a que irremediablemente se lo apropiaron durante 17 años y esa es otra historia que hay que aceptar y esclarecer.

Por todo lo expuesto, el estudio que realizamos responde a un trabajo en torno a "identidades avasalladas y silenciadas" 59 , identidades negadas de las cuales urge ocuparse y esclarecer los relatos avergonzados y criminalizados. En los gobiernos de Ricardo Lagos y Michelle Bachelet (2000-2010), hubo intentos de crear una esfera pública tendiente a la construcción de una "memoria real", que en palabras de Andreas Huyssen buscó

\footnotetext{
${ }^{58}$ Todorov, Tzvetan. Los abusos de la memoria. Madrid, España: Paidós, 2000, p. 18

${ }^{59}$ Marina Franco \& Florencia Levín. Op. cit, p.41
} 
contrarrestar aquellas políticas que a través del olvido intentaron institucionalizar una reconciliación ${ }^{60}$. La memoria de la UP hasta el momento del incendio, solo estaba encarnada en grupos supervivientes, en la dialéctica del recuerdo con la amnesia, en el “margen", en el estratégico espacio del silencio que permite a estas memorias subterráneas esperar el momento indicado para disputar sentidos y representaciones en el espacio público. Al decir de Pierre Nora, las memorias son capaces de "largas latencias y repentinas revitalizaciones" 61 .

En definitiva, la memoria se enraíza transformando casas, estadios, centros culturales, calles, universidades, edificios, en trincheras de los vencidos, en los espacios desde los cuales no sólo se puede narrar el horror o la necesidad de que esos hechos de violencia no vuelvan a ocurrir. Sino que también, por un lado, son ruinas en disputa, que permiten revertir criminalizaciones, obligar nuevos juicios y combates por la Historia. Para en último caso, no solo ser ejemplos o testimonios de la dominación, sino también, se transforman en apropiación "justa y solidaria del espacio territorial y del tiempo histórico",62.

\section{Bibliografía}

Alessandro Portelli, Historias orales. Narración, imaginación y diálogo, Rosario, Argentina: Prohistoria ediciones - FaHCE UNLP, 2016

Alessandro, Portelli, La orden ya fue ejecutada. Roma, las fosas ardeatinas, la memoria, Buenos Aires, Argentina: FCE, 2004

Amaro Barriga, Manuel. "EL MITO EN LA CONSTRUCCIÓN CULTURAL”. Fides et Ratio Revista de Difusión cultural y científica de la Universidad La Salle en Bolivia. Fides Et Ratio v.2 n.2 La Paz sep., 2008 ISSN 2071-081X http://www.scielo.org.bo/scielo.php?script=sci_arttext\&pid=S2071-081X2008000100003., p.15

Andrea Huyssen, En busca del futuro perdido. Cultura y memoria en tiempos de globalización. México DF: Fondo de Cultura Económica México, 2002.

Carlos Altamirano. "Pasado presente". En Lida, Clara; Crespo, Horacio y Yankelevich, Pablo. Argentina 1976, Estudios entorno al Golpe de Estado. México D.F.: El Colegio de México, Centro de Estudios Históricos, 2007.

Dominick LaCapra. Historia y memoria después de Auschwitz. Buenos Aires, Argentina: Prometeo libros. 2009

\footnotetext{
${ }^{60}$ Andrea Huyssen, En busca del futuro perdido. Cultura y memoria en tiempos de globalización. México DF: Fondo de Cultura Económica México, 2002.

${ }^{61}$ Pierre Nora. Les Lieux de mémoire. Santiago: LOM ediciones, 2009, p. 20

${ }^{62}$ Hugo, Achugar. "El lugar de la memoria, a propósito de Monumentos (motivos y paréntesis)". En Langland, V. \& Jelin, E., (Comps). Monumentos, memoriales y marcas territoriales. Madrid, España: Siglo XXI editores, 2003, p. 179
} 
Elizabeth, Jelin. Los trabajos de la memoria. Madrid: Siglo XXI. 2002

Elías Gabriel Sánchez González. "Las huellas del Pasado Reciente de Santiago de Chile. Historia(s) y Memoria(s) del Centro Cultural Gabriela Mistral (GAM) 1971-2010". En Flier, Patricia (Ed.): Dilemas, apuestas y reflexiones teórico-metodológicas para los abordajes en Historia Reciente. FaHCE-UNLP: Ensenada, Argentina 2014, pp. 168-196

Elías Gabriel Sánchez González. Juicio al Edificio Diego Portales. ¿Salvarlo o reemplazarlo? Incendio y reconversión del Centro Cultural Gabriela Mistral (2006-2010) como huellas del pasado reciente de Santiago de Chile. Tesis para optar al grado de Magister en Historia y Memoria. Facultad de Humanidades y Ciencias de la Educación, Universidad Nacional de La Plata. 2017. http://sedici.unlp.edu.ar/handle/10915/65181

Enzo Traverso. "Historia y Memoria". Notas sobre un debate. En M. Franco, \& F. Levín, Historia Reciente. Perspectivas y desafios para un campo en construcción. Buenos Aires: Paidos.2007, p.72 Frank Ankersmit, Experiencia histórica sublime, Santiago de Chile: Palinodia, 2008.

Gabriel Salazar; Julio Pinto, Historia contemporánea de Chile I, Estado, legitimidad, ciudadanía, Santiago, Chile: LOM, 1999

Gustavo, Becerra \& Nancy Rocío, "Mito e historia", Revista Vínculos, V. 11 número 1, Revista distrital Francisco José de Caldas, Colombia: 2014

Gonzalo Carrasco. "Blanqueando, borrando, cubriendo: el edificio del UNCTAD III y las evidencias de un tiempo fracturado". En Matías Allende \& Carol Illanes (Comps.), Trabajo en Utopía. Monumentalidad arquitectónica en el Chile de la Unidad Popular. Santiago de Chile: Adrede editora, 2014.

Hayden White, Metahistoria, La imaginación histórica en la Europa del Siglo XIX, D.F. México: FCE, 1992

Hugo, Achugar. "El lugar de la memoria, a propósito de Monumentos (motivos y paréntesis)". En Langland, V. \& Jelin, E., (Comps). Monumentos, memoriales y marcas territoriales. Madrid, España: Siglo XXI editores, 2003

Isabel Jara Hinojosa. "Graficar una "segunda independencia": El régimen militar chileno y las ilustraciones de la Editorial Nacional Gabriela Mistral". Historia $\mathrm{N}^{\circ}$ 44, Vol. I, Santiago de Chile, enero-junio: 2011 pp. 131-163 http://www.scielo.cl/scielo.php?script=sci_arttext\&pid=S071771942011000100004

José Llanos. "Conversación con los Arquitectos de la UNCTAD III, Hugo Gaggero y José Covacevic". En Varas, P., \& Llano, J. 275 días. Sitio, Tiempo, Contexto y Afecciones Afectivas. Santiago: Ograma - MOP, 2011.

Luis Hernán Errázuriz; Gonzalo Leiva Quijada. El Golpe Estético, Dictadura Militar en Chile, 1973-1989. Santiago de Chile: Editorial Ocho Libros. 2011 
Michael, Löwy. Walter Benjamin: aviso de incendio, Una lectura de las tesis "sobre el concepto de historia”, Buenos Aires: FCE, 2003

Nora Rabotnikof. "Mito político y memorias de la política", en María Inés Mudrovcic (editora). Pasados en conflicto. Representación, mitos y conflicto. Argentina: Prometeo libros, 2009

Paul Ricoeur. La memoria, la historia, el olvido. Buenos Aires: Fondo de Cultura Económica, 2010.

Paulina Varas. "El nosotros como arte incorporado a la arquitectura y como arte incorporado a la vida". En Paulina Varas; José Llanos. 275 días. Sitio, Tiempo, Contexto y Afecciones Afectivas. Santiago: Ograma - MOP, 2011

Pierre, Nora. Les Lieux de mémoire. Santiago: LOM ediciones, 2009

Raposo, A., Valencia, M., \& Raposo, G. La interpretación de la Arquitectura. Historia de las realizaciones habitacionales de la Corporación de Mejoramiento Urbano CORMU en Santiago, 1966-1976. Santiago: LOM. 2005

Roland, Barthes. Mitologías. España, Siglo XXI editores. 1999.

Todorov, Tzvetan. Los abusos de la memoria. Madrid, España: Paidós, 2000

\section{Entrevistas / Testimonios}

Entrevista al Arq, Miguel Lawner, realizada en diciembre del 2012 por Elías Sánchez en Santiago de Chile.

Entrevista al Arq. Jorge Wong, realizada en diciembre del 2014 por Elías Sánchez en Santiago de Chile.

Encuentro sobre UNCTAD III. Textos Protagonistas. Lawner, Miguel (2010); Assler, Federico (2010); Bustamante, Manuel (2010); Frías, Miguel (2010). Presentación del proyecto curatorial Museo de la Memoria y los Derechos Humanos, Santiago, junio 2010. En Varas, P., \& Llano, J. (2011). 275 días. Sitio, Tiempo, Contexto y Afecciones Afectivas. Santiago: Ograma - MOP.

Wong, Jorge (2010). Edificio UNCTAD III. En Varas, P., \& Llano, J. (2011). 275 días. Sitio, Tiempo, Contexto y Afecciones Afectivas. Santiago: Ograma - MOP.

Guerra, Eduardo (2011). Conversaciones con Eduardo Guerra, entrevista realizada por Paulina

Varas En Varas, P., \& Llano, J. (2009). 275 días. Sitio, Tiempo, Contexto y Afecciones Afectivas. Santiago: Ograma - MOP.

Assler, Federico (2013). Entrevista de Equipo Plataforma Urbana. "La escultura de Federico Assler que hoy volvió a ser de los ciudadanos. Plataforma Urbana, 29 de Octubre, 2013

http://www.plataformaurbana.cl/archive/2013/10/29/la-escultura-de-federico-assler-que-hoy-volvioa-ser-de-los-ciudadanos/ 


\section{Archivo Nacional y Biblioteca Nacional}

Allende, Salvador (3 de abril de 1972). Discurso del Presidente de La República, compañero Salvador Allende Gossens, en la inauguración del Edificio de la UNCTAD III. Embajada de Chile, Centro de Documentación, Oficina de informaciones de la presidencia. Fundación Salvador Allende.

(7 de abril de 1972). Discurso del Presidente de La República, compañero Salvador Allende Gossens, en el acto de homenaje a los trabajadores de la construcción del Edificio de UNCTAD III. Embajada de Chile, Centro de Documentación, Oficina de informaciones de la presidencia. Fundación Salvador Allende.

Boletín 65, abril-mayo 1972. "Comisión Chilena UNCTAD III”. Editorial Quimantú: Santiago de Chile, 1972. Biblioteca Nacional, sección chilena

Boletín de la UNCTAD III. "Chile capital del mundo". Santiago de Chile, 1972. Archivo Nacional de Chile, Sección chilena.

El Mercurio (12 de agosto de 2007). "Juicio al edificio Diego Portales: ¿Salvarlo o reemplazarlo?”. Sección Artes y Letras, Cultura, Cuerpo E. Santiago de Chile: Biblioteca Nacional, sección periódicos.

Felipe Herrera. Edificio sede para UNCTAD III. Centro Cultural Metropolitano de Santiago. Biblioteca Nacional, sección chilena 1972.

Román, Silva. El Tercer Mundo, UNCTAD III y Los Trabajadores. Comisión chilena para la UNCTAD III. Biblioteca Nacional, sección chilena: Santiago 1972

Rojahelis, Javier (12 de agosto de 2007). "Proyecto arquitectónico, ¿otro centro cultural deficitario? Reconstruyendo desde las cenizas el "Diego Portales". Sección Artes y Letras, Cultura, Cuerpo E. Santiago de Chile: Biblioteca Nacional, sección periódicos. 